\title{
Morphology, mating system and taxonomy of Volvox africanus (Volvocaceae, Chlorophyceae) from Thailand
}

Hisayoshi Nozaki ${ }^{1,2^{*}} \mathbb{D}$, Wuttipong Mahakham ${ }^{3}$, Wirawan Heman ${ }^{4}$, Ryo Matsuzaki ${ }^{2,5}$ and Masanobu Kawachi ${ }^{2}$

\begin{abstract}
Background: The oogamous green algal genus Volvox exhibits extensive diversity in mating systems, including heterothallism and homothallism with unisexual (male and/or female) and/or bisexual spheroids. Although four mating systems have been recognized worldwide in strains identified as "Volvox africanus", most of these strains are extinct. However, we previously rediscovered two types of the four mating systems (heterothallic, and homothallic with male and bisexual spheroids within a clone) from an ancient Japanese lake, Lake Biwa.

Results: Here, we obtained strains exhibiting the third mating system (homothallic with unisexual male and female spheroids within a clone) from a freshwater area of Kalasin Province, Thailand. When sexual reproduction was induced in the present Thai strains, both male and female unisexual spheroids developed to form smooth-walled zygotes within a clonal culture. Phylogenetic analyses of the internal transcribed spacer region-2 of nuclear ribosomal DNA sequences from all four mating systems, including the extinct strains, resolved the third mating system is basal or paraphyletic within the homothallic clade.

Conclusions: The present morphological and molecular data of the Thai strains indicate that they belong to the homothallic species $V$. africanus. The phylogenetic results suggested that third mating system (homothallic with separate male and female sexual spheroids) may represent an initial evolutionary stage of transition from heterothallism to homothallism within Volvox africanus. Further field collections in geologically stable intracontinental regions may be fruitful for studying diversity and taxonomy of the freshwater green algal genus Volvox.
\end{abstract}

\section{Background}

Evolutionary transitions in the mating systems of a wide range of eukaryotic taxa are a crucial topic in the biological sciences (Wittenberger 1979; Barrett 2010). Freshwater algae are convenient research materials for examining sexual habit, as sexual reproduction can be easily induced under controlled laboratory conditions (Stein 1973). Thus, classical genetic studies of algae have primarily used the unicellular green algal genus Chlamydomonas (Harris 1989), and subsequent extensive molecular

\footnotetext{
*Correspondence: nozaki@bs.s.u-tokyo.ac.jp

1 Department of Biological Sciences, Graduate School of Science, The

University of Tokyo, Bunkyo-ku, Tokyo, Japan

Full list of author information is available at the end of the article
}

genetic studies of $C$. reinhardtii resolved its mating-type locus and mating-type specific genes (Ferris and Goodenough 1994, 1997). Chlamydomonas species are isogamous without differentiation between males and females, but the closely related multicellular volvocine lineage includes anisogamous genera and the oogamous genus Volvox that are diverse in their mating systems (Harris 1989; Hanschen et al. 2018).

Starr (1971) reported four mating systems in worldwide strains of a volvocine alga identified as the single species "Volvox africanus" ("VxAf"). Although Coleman (1999) analyzed the internal transcribed spacer region (ITS)-2 of nuclear ribosomal DNA (rDNA) sequences from the four mating systems of "VxAf", most of the "VxAf" strains deposited in UTEX (Starr and Zeikus 1993) were 
unavailable (Nozaki et al. 2015a). This problem was partially resolved when new "VxAf" strains representing the two mating systems were established from field-collected water samples in an ancient Japanese lake, Lake Biwa (Nozaki et al. 2015a). One of the two types is homothallic with male and bisexual spheroids and was identified as Volvox africanus G.S. West, whereas the other has been described as the new heterothallic species Volvox reticuliferus Nozaki (Nozaki et al. 2015a) (Table 1). However, details of morphology and sexual reproduction of "VxAf" strains with the other two mating systems (homothallic with separate male and female sexual spheroids, and homothallic with only bisexual spheroids) have remained unresolved.

Very recently, we obtained "VxAf" strains of the third mating system (homothallic with separate male and female sexual spheroids; Table 1) from a freshwater habitat in Kalasin Province, in the interior continental region of Thailand. Our morphological and phylogenetic data identified these Thai strains as $V$. africanus, and this type of homothallic mating system may be ancestral within $V$. africanus. The morphology, mating system, and taxonomy of these homothallic strains of $V$. africanus are described in this report.

\section{Methods}

Establishment of cultures and morphological observations Water samples ( $\mathrm{pH} \mathrm{6.85}$; temperature $30.5^{\circ} \mathrm{C}$ ) were collected from a marsh in Nong Ya Ma, Yang Talat District, Kalasin Province, Thailand (16 $28^{\prime} 14.55^{\prime \prime} \mathrm{N}, 103^{\circ} 16^{\prime}$ $25.55^{\prime \prime}$ E) on 1 November 2019. Clonal cultures of $V$. africanus (strains 1101-NK-1 and 1101-NZ-11) were established from the water sample using the pipette washing method (Pringsheim 1946). The strains are available as NIES-4467 (1101-NK-1) and NIES-4468 (1101-NZ-11) in the Microbial Culture Collection of the National Institute for Environmental Studies, Japan (Kawachi et al. 2013). Cultures were grown in $18 \times 150-\mathrm{mm}$ screw-cap tubes containing 10-11 mL artificial freshwater-6 (AF6) or Volvox thiamin acetate (VTAC) medium (Kawachi et al. 2013), at $25^{\circ} \mathrm{C}$ under a 14:10-h light:dark schedule, under cool-white fluorescent lamps (with a color temperature of $5000 \mathrm{~K})$ at an intensity of $80-130 \mu \mathrm{mol} \mathrm{m} \mathrm{m}^{-2} \mathrm{~s}^{-1}$. The cultures were initially maintained in AF- 6 medium. For morphological observations, possible contaminant bacteria were removed from the cultures by squeezing a young, unhatched spheroid out of the parental spheroid and washing the spheroid using the pipette washing method. The young spheroid was then grown in 10-11 mL VTAC medium. Asexual spheroids were observed in actively growing cultures in VTAC medium, as described previously (Nozaki et al. 2015a). To induce production of sexual spheroids, $0.3-0.8 \mathrm{~mL}$ actively growing culture in VTAC medium (the volume depended on the number and density of spheroids in the culture) at $25^{\circ} \mathrm{C}$ were inoculated with $10-11 \mathrm{~mL}$ urea soil Volvox thiamine medium (Nozaki et al. 2015b). This culture was then grown at $20{ }^{\circ} \mathrm{C}$ under a 14:10-h light:dark schedule under cool-white fluorescent lamps at an intensity of $50-70 \mu \mathrm{mol} \mathrm{m}^{-2} \mathrm{~s}^{-1}$. Sexual spheroids usually developed within 20 days. Light microscopy was conducted using the BX60 microscope (Olympus, Tokyo, Japan) equipped with Nomarski interference optics. To examine the form of individual sheaths in the gelatinous matrix in spheroids, approximately $20 \mu \mathrm{L}$ cultured material was mixed with $4-10 \mu \mathrm{L} 0.002 \%$ (w/v in distilled water) methylene blue (1B-429 Waldeck GmbH \& Co Division Chroma, Münster, Germany). Spheroid cells were counted as described previously (Smith 1944; Nozaki 1988; Nozaki et al. 2019).

Table 1 Four types of mating systems and their taxonomy in "VxAf" (Volvox africanus and V. reticuliferus)

\begin{tabular}{|c|c|c|c|c|}
\hline $\begin{array}{l}\text { Mating system } \\
\text { (Abbreviation) }\end{array}$ & $\begin{array}{l}\text { Heterothallic mating } \\
\text { system (Hetero) }\end{array}$ & $\begin{array}{l}\text { Homothallic mating } \\
\text { system I (Homo I) }\end{array}$ & $\begin{array}{l}\text { Homothallic mating } \\
\text { system II (Homo II) }\end{array}$ & $\begin{array}{l}\text { Homothallic mating system } \\
\text { III (Homo III) }\end{array}$ \\
\hline Sexual spheroids produced & $\begin{array}{l}\text { Male and female spheroids } \\
\text { by different genotypes }\end{array}$ & $\begin{array}{l}\text { Male and bisexual spheroids } \\
\text { by a single genotype }\end{array}$ & $\begin{array}{l}\text { Male and female spheroids } \\
\text { by a single genotype }\end{array}$ & Bisexual spheroids \\
\hline $\begin{array}{l}\text { Individual sheaths of the } \\
\text { spheroid matrix }\end{array}$ & Confluent or indistinct & Distinct & Distinct & - \\
\hline Zygote walls & Reticulate & Smooth & Smooth & - \\
\hline Volvox species classified & V. reticuliferus & V. africanus & V. africanus & V. africanus \\
\hline $\begin{array}{l}\text { Strains [origins] analyzed in } \\
\text { this study (Figs. } 3,4)\end{array}$ & $\begin{array}{l}\text { NIES-3781, NIES-3782, NIES- } \\
3783 \text { [Lake Biwa, Japan]; } \\
\text { UTEX 1890-1891 [Small } \\
\text { pond, Australia] }\end{array}$ & $\begin{array}{l}\text { NIES-3780 [Lake Biwa, } \\
\text { Japan], UTEX } 1893 \text { [Dry } \\
\text { pond, India] }\end{array}$ & $\begin{array}{l}\text { 1101-NK-1 (=NIES-4467), } \\
1101-N Z-11 \text { (=NIES-4468) } \\
\text { [Marsh, Thailand]; UTEX } \\
1889 \text { [Shallow pond, USA] }\end{array}$ & $\begin{array}{l}\text { UTEX } 1892 \text { [Ecca Pass, South } \\
\text { Africa] }\end{array}$ \\
\hline References & $\begin{array}{l}\text { Starr (1971), Nozaki et al. } \\
\text { (2015a) }\end{array}$ & $\begin{array}{l}\text { Starr (1971), Nozaki et al. } \\
(2015 a)\end{array}$ & $\begin{array}{l}\text { Starr (1971), the present } \\
\text { study }\end{array}$ & Starr (1971) \\
\hline
\end{tabular}



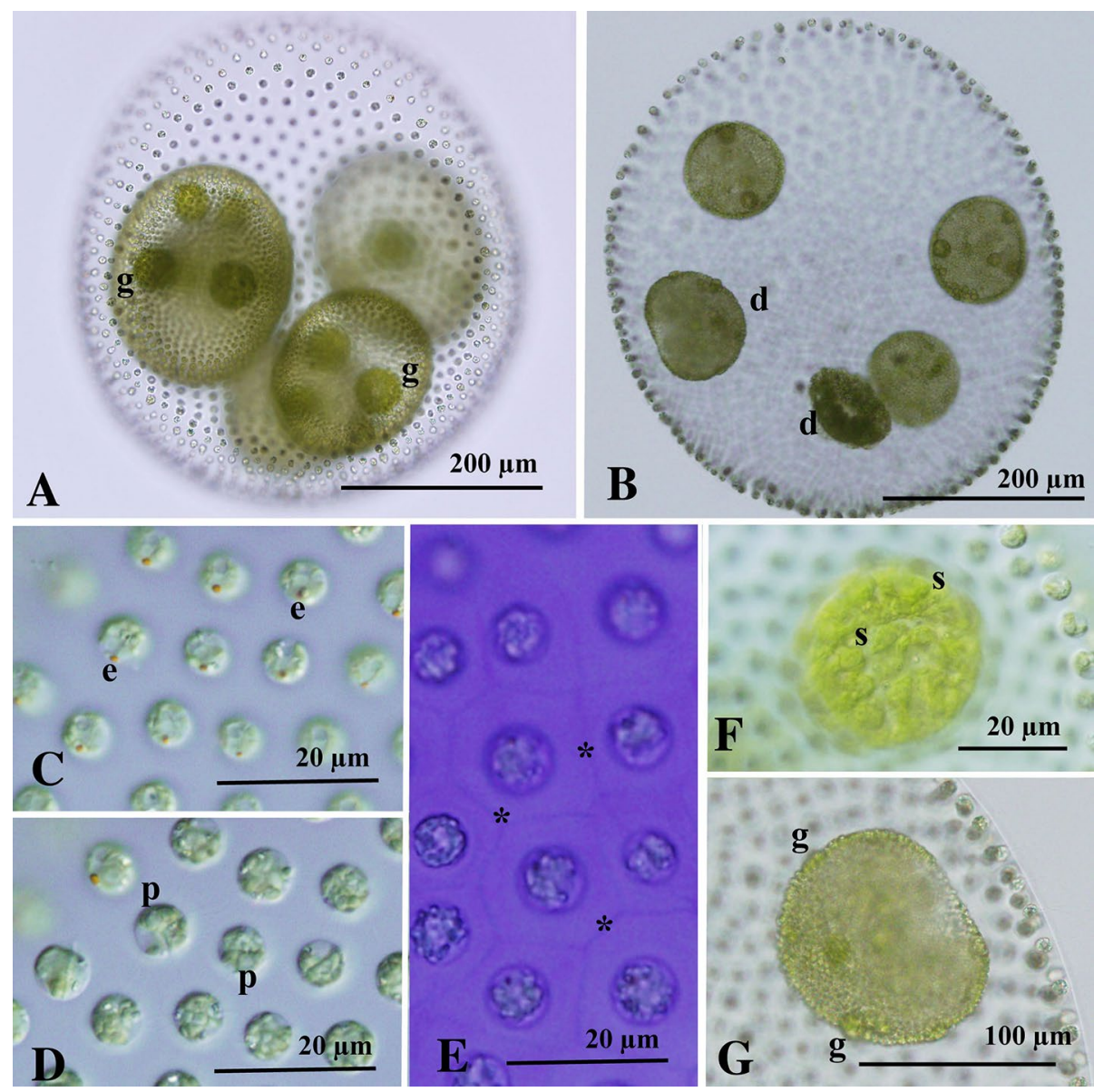

Fig. 1 Asexual spheroids of Volvox africanus G.S. West strains 1101-NK-1 (A) and 1101-NZ-11 (B-G) from Thailand. A, B, E, G Bright-field microscopy. C, D, F Nomarski differential interference contrast microscopy. A Parental spheroid containing daughter spheroids with gonidia (g). B Parental spheroid with developing embryos (d). C-E Part of spheroids. C Surface view of somatic cells showing an eyespot (e). D Optical section of somatic cells showing a pyrenoid (p) in the chloroplast. E Front view of somatic cells with individual sheaths (asterisks). Stained with methylene blue. F Surface view of gonidium showing radial striations (s). G Pre-inversion embryo or plakea. Note that differentiation of gonidia (g) of the next generation is evident

For transmission electron microscopy, an actively growing cultured sample was pre-fixed with $1 \%$ glutaraldehyde and post-fixed with $2 \% \mathrm{OsO}_{4}$ and examined as in the previous study (Nozaki et al. 2015a) except for using $4 \%$ samarium chloride solution in distilled water instead of saturated solution of uranyl acetate (Matsuzaki et al. 2014).

\section{Molecular experiments}

To infer the phylogenetic position and origin of the Thai strains of $V$. africanus, we analyzed ITS-2 and 6021 base pairs of the coding regions of five chloroplast genes (large subunit of RuBisCO, adenosine triphosphate synthase beta subunit, photosystem I P700 chlorophyll a apoprotein A1, photosystem I P700 chlorophyll a apoprotein A2, and photosystem II CP43 reaction center protein genes) as in previous studies (Nozaki et al. 2015a; Yamamoto et al. 2021), except that the alignments included an additional operational taxonomic unit of the Thai strains of $V$. africanus. New sequences from the Thai strains were determined based on direct sequencing of polymerase chain reaction products, as described previously (Nozaki et al. 2015a; Yamamoto et al. 2021), and are available under Accession numbers LC631309-LC631310 (ITS rDNA for 1101-NZ-11 and 1101-NK-1) and LC631311LC631315 (five chloroplast genes for 1101-NZ-11). The alignments of ITS-2 and the five chloroplast genes are available from TreeBASE (https://reebase.org/treebaseweb/home.html; study ID: 28191). Designation of the outgroup was performed as described previously (Nozaki et al. 2015a; Yamamoto et al. 2021). Maximum-likelihood analyses based on the ITS rDNA and chloroplast multigene alignments were performed using MEGA X (Kumar et al. 2018), with 1000 replicates of bootstrap analyses 


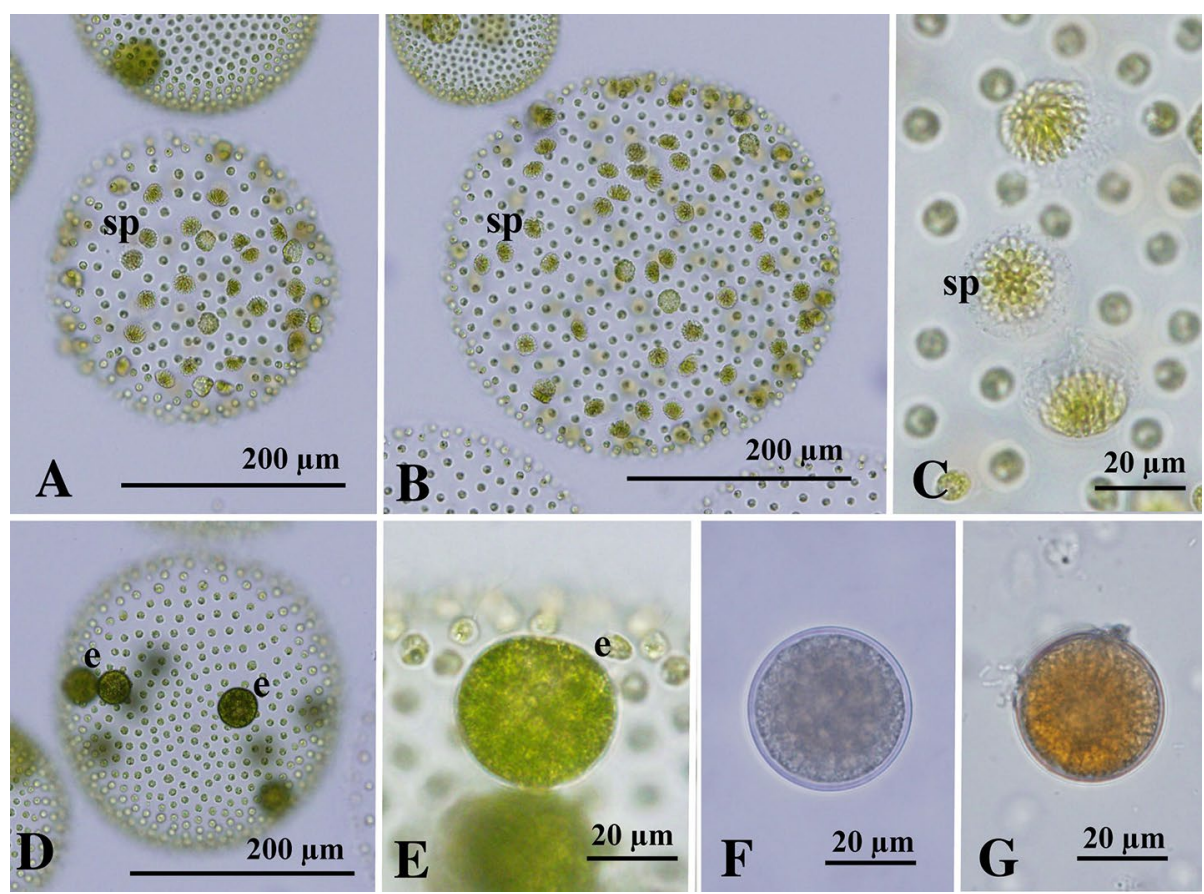

Fig. 2 Sexual spheroids of Volvox africanus G.S. West strains 1101-NK-1 (A-F) and 1101-NK-1 x 1101-NZ-11 (G) from Thailand. A-G Bright-field microscopy. A-C Male spheroids with sperm packets (sp). D, E Female spheroids with eggs (e). F, G Mature zygotes with a smooth cell wall

(Felsenstein 1985). In addition, Bayesian inference of ITS-2 was conducted using MrBayes 3.2.7a (Ronquist et al. 2012), as described in a previous study (Nozaki et al. 2015a). Timetree analysis was performed using the chloroplast multigene data set by MEGA X, as in a previous study (Yamamoto et al. 2021). The secondary structures of ITS-2 were predicted as described previously (Nozaki et al. 2015a).

\section{Results}

\section{Asexual spheroids}

The Thai strains of $V$. africanus produced asexual spheroids that were ovoid, subspherical, or ellipsoidal in shape (Fig. 1A, B). The spheroid was up to $550 \mu \mathrm{m}$ in length and consisted of approximately 1500-6000 somatic cells and 2-8 reproductive cells (gonidia). Gonidia were generally arranged in one or two tiers. When arranged in two tiers, one was positioned primarily at the equator of the spheroids and the other within the posterior half of the spheroid (Fig. 1A, B); the gonidia of the posterior tier often showed delayed embryogenesis. The cells lacked cytoplasmic bridges between them and were embedded in individual sheaths at the periphery of the gelatinous matrix (Fig. 1C, D). Individual sheaths were rectangular or hexagonal in shape and compactly arranged without fenestrations between them in the frontal view (Fig. 1E). Somatic cells had two equal flagella and a cup-shaped chloroplast with a single basal pyrenoid and a single eyespot, and they measured up to $8 \mu \mathrm{m}$ in length (Fig. 1C, D). Gonidia had radial striations on the surface of the chloroplast in the frontal view (Fig. 1E). During the plakeal stages of the developing embryo, gonidia of the next generation were evident (Fig. 1G).

\section{Sexual spheroids}

Both male and female sexual spheroids were unisexual and developed within a single clonal culture. Male spheroids were generally 500-1300-celled and subspherical or ovoid in shape, with 60-100 sperm packets distributed almost throughout the surface of the spheroid (Fig. 2A, B). Sperm packets were hemispherical in shape and were composed of approximately 100-200 spindle-shaped male gametes (sperm) (Fig. 2C). Female spheroids contained 500-1500 cells and usually 7-11 eggs within the posterior three-fifths (Fig. 2D, E). Production of zygotes (thick-walled cells) were rare under the present culture conditions, but they were found even within the single clonal culture. Zygotes measured approximately $30 \mu \mathrm{m}$ in diameter and had a smooth cell wall (Fig. 2F, G).

\section{Transmission electron microscopy}

The entire spheroid of the present Thai strain was surrounded by a tripartite boundary (colonial boundary) of 

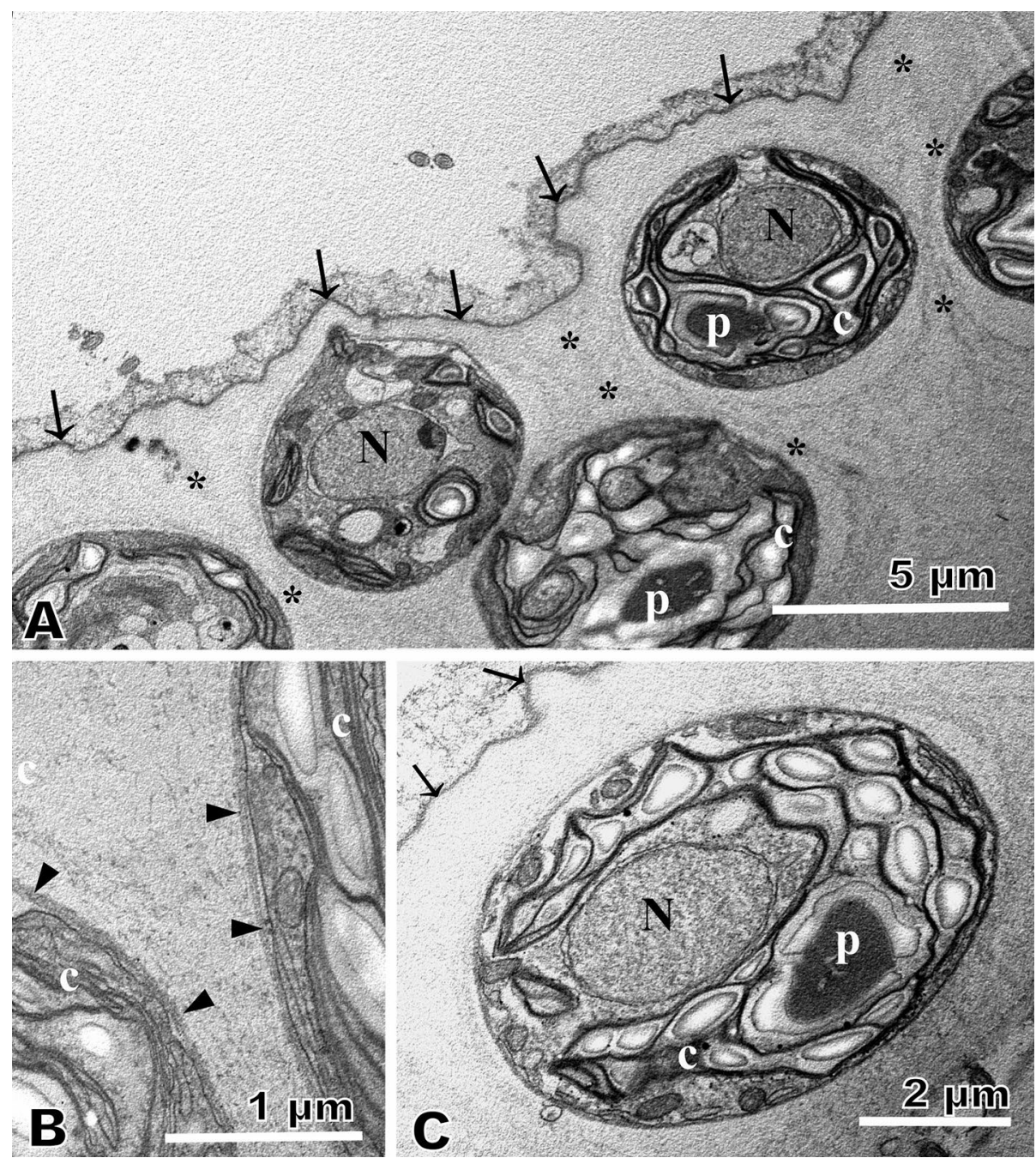

Fig. 3 Transmission electron microscopy of asexual spheroids of Volvox africanus G.S. West strain 1101-NZ-11 from Thailand. A-C Whole spheroid is surrounded by a tripartite layer (colonial boundary) of the extracellular matrix (arrows). Each protoplast is enclosed tightly by a thin layer (cellular envelope) of the matrix (arrowheads) and has a nucleus ( $\mathrm{N}$ ) and a chloroplast (c) with a pyrenoid (p). Note that the matrix between cells forms individual sheath (asterisks). A Section of peripheral region showing cells and extracellular matrix. B Details of cellular envelopes. C Longitudinal section of a cell

the extracellular matrix as (Fig. 3A) as in other volvocacean algae (Nozaki and Kuroiwa 1992). Just beneath the colonial boundary, cells were observed with profiles of a chloroplast, mitochondria, and a nucleus inside the cell membrane (Fig. 3A-C). Each cell was tightly enclosed by a thin layer [cellular envelope (Nozaki and Kuroiwa 1992)] of the matrix (Fig. 3B). At the peripheral region of the spheroid, the matrix within the space between the cells formed a fibrillar layer (Fig. 3A) as in V. africanus from Lake Biwa (Nozaki et al. 2015a), representing the individual sheath observed under the light microscopy (Fig. 1E).

\section{Phylogenetic analyses}

Based on the chloroplast multigene data set, phylogenetic relationships within the anisogamous/oogamous members of the colonial volvocine algae [Eudorina group (Nozaki et al. 2015a)] were resolved as described in a previous study (Yamamoto et al. 2021), except for the addition of the Thai strain of $V$. africanus. Four different isolates of "VxAf" formed a robust monophyletic group ("VxAf" lineage) within Volvox sect. Merrillosphaera (Fig. 4). The "VxAf" lineage was subdivided into two sister groups: one homothallic $V$. africanus composed of the Japanese and Thai strains and the other two strains of 


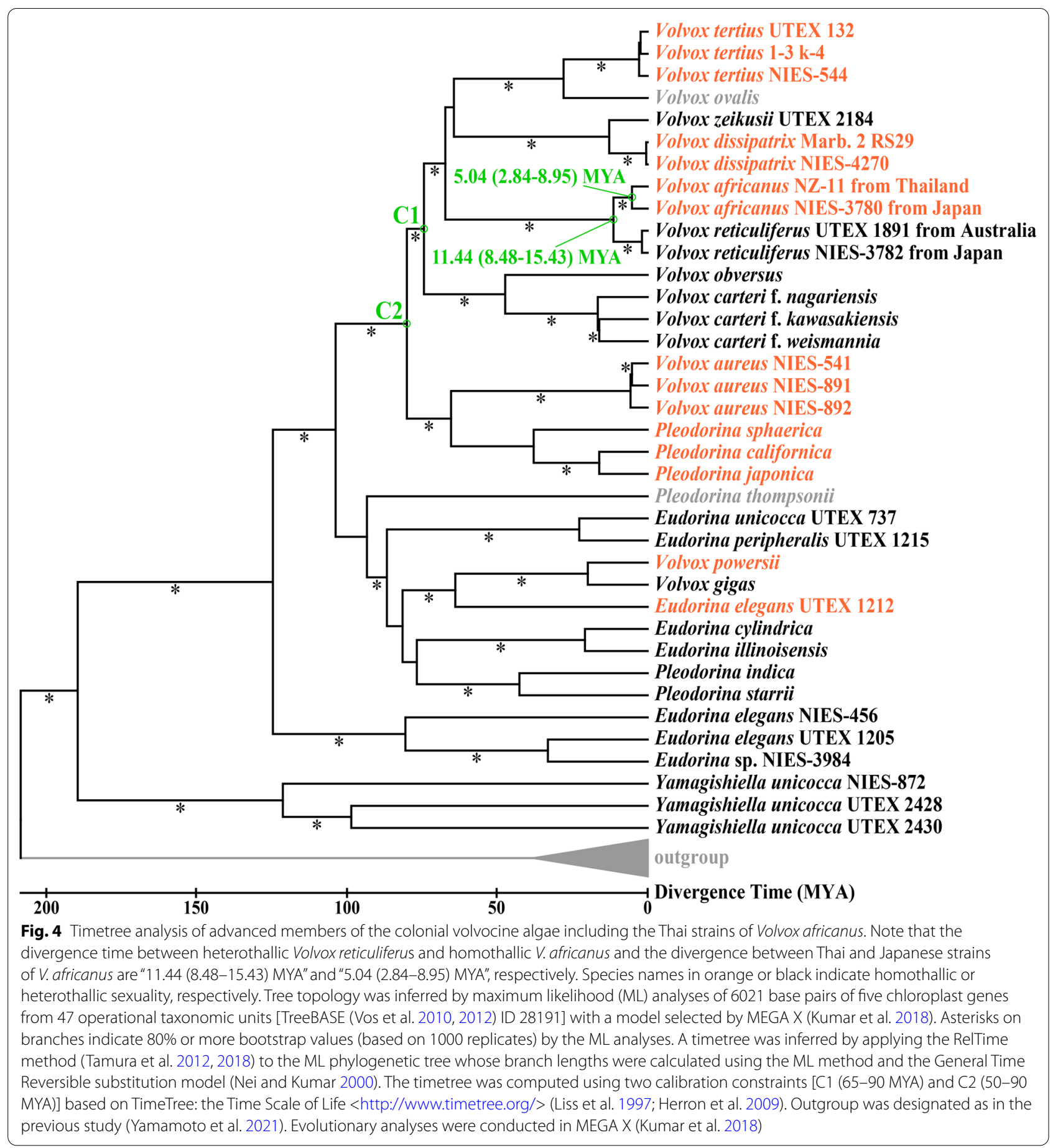

heterothallic $V$. reticuliferus. Our timetree analysis dated the origin of "VxAf" and the separation between Thai and Japanese strains of $V$. africanus as approximately 11 MYA and 5 MYA, respectively (Fig. 4).

The ITS-2 phylogenetic analysis included five "VxAf" strains of UTEX [Culture Collection of Algae at the University of Texas at Austin (Starr and Zeikus 1993)], in which Starr (1971) observed four mating systems (Fig. 5). As in the chloroplast multigene phylogeny, two sister clades were resolved in the "VxAf" lineage: homothallic $V$. africanus and heterothallic $V$. reticuliferus (Fig. 5). However, the most basal position of UTEX 1889 within the homothallic clade was moderately resolved (with only a $73 \%$ bootstrap value using the maximum-likelihood 


VIES-3781 (Hetero, Japan)
NIES-3782 (Hetero, Japan)
NIES-3783 (Hetero, Japan)

method) (Fig. 5). The strains of two homothallic mating systems with production of bisexual spheroids (Homo I and III, with and without male unisexual spheroids, respectively) constituted a derived lineage, to which two non-sister strains [Thai and Missouri (UTEX 1889; Starr 1971) strains] of the homothallic mating system with male and female unisexual spheroids were basal (Fig. 5).

\section{Compensatory base changes (CBCs) in nuclear rDNA ITS-2} As resolved previously (Nozaki et al. 2015a), CBCs were not detected in the most highly conserved region of nuclear rDNA ITS-2 [helix III (Nozaki et al. 2015a)] among operational taxonomic units within the heterothallic clade identified as V. reticuliferus (Fig. 6). However, the Thai strains or UTEX 1889 had two or three CBCs compared with other strains within the homothallic clade identified as $V$. africanus (see below) (Fig. 6).

\section{Discussion}

\section{Taxonomy}

Volvox reticuliferus is clearly distinguished from $V$. africanus, based on its morphological traits (reticulate zygote walls and confluent or indistinct individual sheaths), heterothallic mating system and phylogeny (Table 1) (Nozaki et al. 2015a). Even though information regarding zygote morphology and/or mating systems is lacking for UTEX 1890, 1891, and 2907 strains, they were identified as $V$. reticuliferus based on vegetative morphology (individual sheaths) and phylogeny (Nozaki et al. 2015a). In the homothallic clade, however, such vegetative morphology has previously been obtained in only one (Homo I) of the three homothallic mating systems of "VxAf" by Starr (1971), due to the extinction of strains belonging to other homothallic mating systems (Homo II and III) (Nozaki et al. 2015a). The present study established new strains of "VxAf" originating from Thailand and revealed their homothallic sexual habit (Homo II) and morphological characteristics (smooth zygote walls and compact and angular individual sheaths; Figs. 1, 2 and 3) that are consistent with those of $V$. africanus (Table 1) (Nozaki et al. 2015a). In addition, the divergence date between mating systems Homo I (Lake Biwa, Japan) and Homo II (Kalasin, Thailand) is younger than those between sister species within the anisogamous/oogamous members of the multicellular volvocine algae (Fig. 4). Thus, "VxAf" strains of all homothallic mating systems (Homo I-III; Table 1) should be classified as $V$. africanus based on their monophyletic status (Figs. 4, 5) and common morphological/ phenotypical characteristics (Table 1), even though their mating systems vary in the production of sexual spheroids (Table 1), and their ITS- 2 rDNA demonstrated the presence of CBCs between them (Fig. 6). This taxonomic conclusion is consistent with the monophyletic morphological species concept in microalgae (Nozaki et al. 1998). 


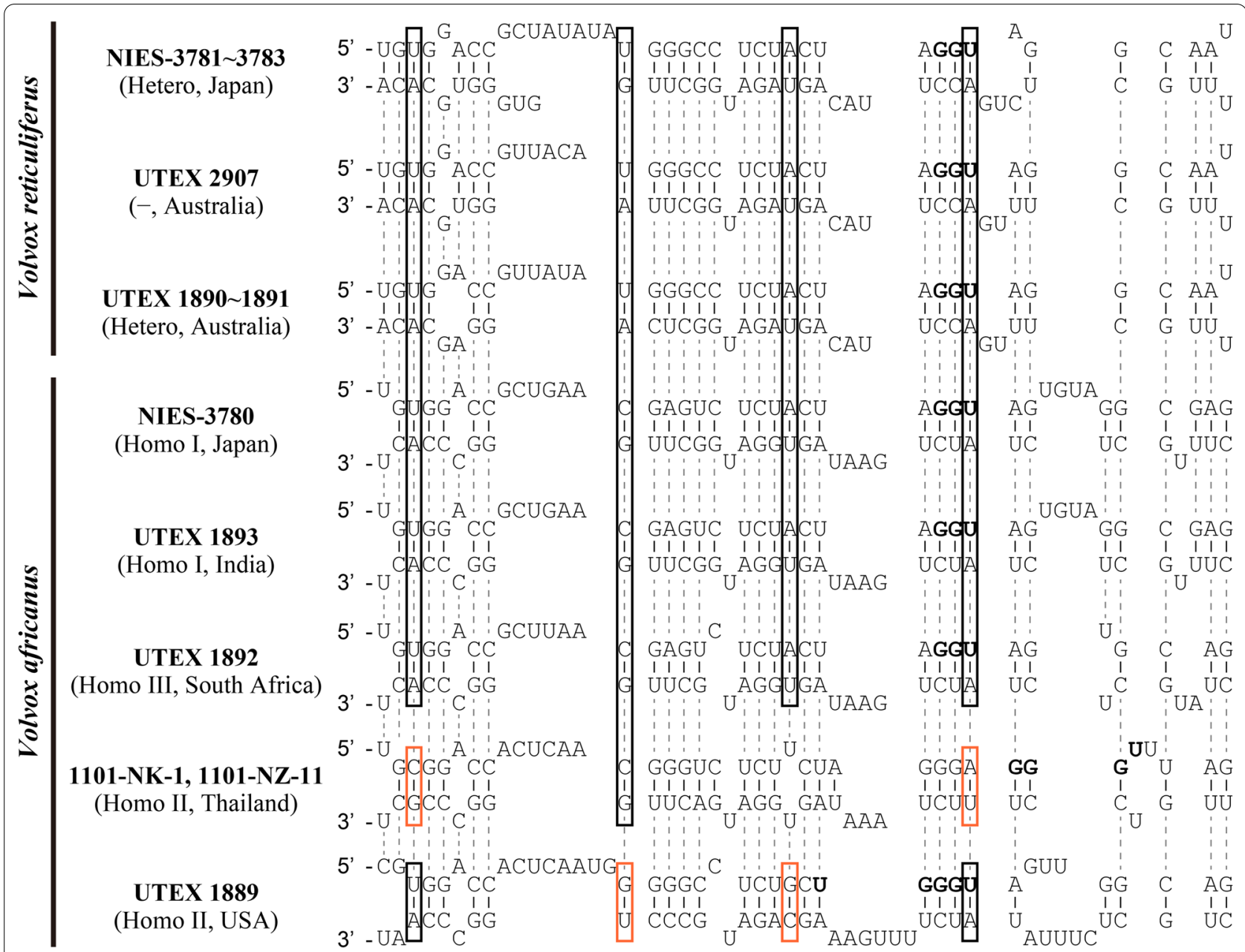

Fig. 6 Comparison of the most conserved region [near the YGGY motif of helix III (Coleman 2009)] of nuclear rDNA ITS-2 secondary structure between strains of four mating systems of Volvox africanus and $V$. reticuliferus (Table 1). Note the modified YGGY motif (boldface). For secondary structures of ITS-2, see Nozaki et al. (2015a). Red and black open boxes indicate compensatory base changes between Homo II strains (from Thailand and USA) and those of other sexual systems

\section{Evolution of homothallic mating systems in Volvox}

Volvocine algae, especially Volvox species are an excellent model for studying the evolution of sexual dimorphism and mating systems. Some species of Volvox are heterothallic species, in which different genotypes produce either eggs or sperm, while others are homothallic species with a single genotype producing both eggs and sperm (Hanschen et al. 2018). The "VxAf" lineage is an excellent model for investigating the evolutionary transition between heterothallism to homothallism as it represents both homothallism and heterothallism within a closely related group (Figs. 4, 5).

Based on the genome comparison of sex-determining regions in male and female determining chromosomes of heterothallic $V$. reticuliferus and the sex-determining region-like region of homothallic $V$. africanus, the evolutionary transition from heterothallism to homothallism in the "VxAf" lineage was unambiguously resolved (Yamamoto et al. 2021). In addition, the present phylogenetic analyses of ITS-2 demonstrated that two strains of the homothallic mating system with separate or unisexual male and female sexual spheroids (Homo II) are basal and paraphyletic and may represent the ancestral state of the homothallism in the "VxAf" lineage (Fig. 5). The heterothallic mating system of "VxAf" ( $V$. reticuliferus) also produces unisexual male and female sexual spheroids as in Homo II (Table 1). Thus, during the initial stage of the evolutionary transition from heterothallism to homothallism in the "VxAf" lineage, the ancestor of the "VxAf" lineage may have first evolved this type of homothallic mating system (Homo II) from the heterothallic mating system (Hetero) without modification of the form of sexual spheroids (unisexual male and female). Bisexual spheroids 
may have subsequently evolved in the homothallic ancestor of the "VxAf" lineage.

\section{Conclusions}

Algal diversity in Kalasin Province shows that freshwater bodies of this region contain a variety of volvocine and other interesting green algae (Heman 2015). The present re-discovery of the homothallic "VxAf" strains with unisexual male and female spheroids is based on field collections in a freshwater habitat of an intracontinental region of Thailand. We also found a new species of Volvox sect. Volvox, $V$. longispiniferus Nozaki \& Mahakham, from the same field collection (Nozaki et al. 2020). In addition, two species of "VxAf" were collected in an ancient lake, Lake Biwa, Japan (Nozaki et al. 2015a). Thus, freshwater habitats in such geologically stable intracontinental regions may be fruitful for Volvox diversity.

\section{Abbreviations}

AF-6: Artificial freshwater-6; "VxAf": "Volvox africanus"; CBC: Compensatory base change; ITS: Internal transcribed spacer region; ML: Maximum likelihood; rDNA: Nuclear ribosomal DNA; VTAC: Volvox thiamin acetate.

\section{Acknowledgements}

We would like to thank Dr. Noppawan Nounjan, Department of Biology, Faculty of Science, Khon Kaen University for her assistance in field collection.

\section{Authors' contributions}

$\mathrm{HN}$ and WM designed the study and WH and MK supervised the project. WM collected wild-samples of Volvox. Cultures of Volvox were established by WM. All the other experiments and data analyses were performed by HN, RM and MK. The manuscript was written by HN and WM and modified by all authors. All authors read and approved the final manuscript.

\section{Funding}

This study was supported by a Grants-in-Aid for Scientific Research (Grant numbers 19K22446 for HN and 20H03299 for HN) from the Ministry of Education, Culture, Sports, Science and Technology (MEXT)/Japan Society for the Promotion of Science (JSPS) KAKENHI (https://www.jsps.go.jp/english/egrants/), and the Applied Taxonomic Research Center (Grant number: ATRC KKUR6309; http://atrc.sc.kku.ac.th/), Department of Biology, Faculty of Science, Khon Kaen University. The funders had no role in study design, data collection and analysis, decision to publish, or preparation of the manuscript.

\section{Data availability}

New sequence data, alignments used for our phylogenetic analyses, and new strains are available under the DDBJ/EMBL-EBI/NCBI Accession numbers (LC631309-LC631315), TreeBASE study ID (28191), and NIES Collection strain designations (NIES-4467-NIES-4468), respectively. All other relevant data are within the paper.

\section{Declarations}

Ethics approval and consent to participate

The study involves no human participants. WM collected the green algal genus Volvox from the water column in a marsh in Thailand. Collection was conducted in accordance with the Plant Variety Protection Act, B.E. 2542 (1999), Section 53, Department of Agriculture, Thailand, which addresses the collection of plants for research, study, or experimentation for non-commercial purposes. The analysis of Thai materials was conducted in accordance with a Memorandum of Understanding between the University of Tokyo and Khon Kaen University for international cooperative research on the systematics, phylogenetics, and evolution of freshwater green algae in Thailand (2017-2021).
A material transfer agreement was arranged between Khon Kaen University and the University of Tokyo, with WM as the provider scientist and HN as the recipient scientist.

\section{Consent for publication}

Not applicable.

\section{Competing interests}

The authors have declared that no competing interests exist.

\section{Author details}

${ }^{1}$ Department of Biological Sciences, Graduate School of Science, The University of Tokyo, Bunkyo-ku, Tokyo, Japan. ${ }^{2}$ Biodiversity Division, National Institute for Environmental Studies, Tsukuba, Ibaraki, Japan. ${ }^{3}$ Department of Biology \& Applied Taxonomic Research Center, Faculty of Science, Khon Kaen University, Khon Kaen, Thailand. ${ }^{4}$ Department of Science and Mathematics, Faculty of Science and Health Technology, Kalasin University, Mueang Kalasin, Thailand.

${ }^{5}$ Faculty of Life and Environmental Sciences, University of Tsukuba, Tsukuba, Ibaraki, Japan.

Received: 25 November 2021 Accepted: 8 January 2022

Published online: 21 January 2022

\section{References}

Barrett SC (2010) Darwin's legacy: the forms, function and sexual diversity of flowers. Philos Trans R Soc Lond B Biol Sci 365:351-368. https://doi.org/ 10.1098/rstb.2009.0212

Coleman AW (1999) Phylogenetic analysis of "Volvocaceae" for comparative genetic studies. Proc Natl Acad Sci USA 96:13892-13897. https://doi.org/ 10.1073/pnas.96.24.13892

Coleman AW (2009) Is there a molecular key to the level of "biological species" in eukaryotes? A DNA guide. Mol Phylogenet Evol 50:197-203. https:// doi.org/10.1016/j.ympev.2008.10.008

Felsenstein J (1985) Confidence limits on phylogenies: an approach using the bootstrap. Evolution 39(4):783-791. https://doi.org/10.1111/j.1558-5646. 1985.tb00420.x

Ferris PJ, Goodenough UW (1994) The mating-type locus of Chlamydomonas reinhardtii contains highly rearranged DNA sequences. Cell 76:1135-1145. https://doi.org/10.1016/0092-8674(94)90389-1

Ferris PJ, Goodenough UW (1997) Mating type in Chlamydomonas is specified by mid, the minus-dominance gene. Genetics 146:859-869

Hanschen ER, Herron MD, Wiens JJ, Nozaki H, Michod RE (2018) Repeated evolution and reversibility of self-fertilization in the volvocine green algae. Evolution 72:386-398. https://doi.org/10.1111/evo.13394

Harris EH (ed) (1989) The Chlamydomonas sourcebook. A comprehensive guide to biology and laboratory use. Academic Press, San Diego

Heman W (2015) Diversity and distribution of algae in Kalasin province, Thailand. A report submitted to The National Research University \& Higher Education Research Promotion (NRU \& HERP), Office of the Higher Education Commission, Thailand

Herron MD, Hackett JD, Aylward FO, Michod RE (2009) Triassic origin and early radiation of multicellular volvocine algae. Proc Natl Acad Sci USA 106:3254-3258. https://doi.org/10.1073/pnas.0811205106

Kawachi M, Ishimoto M, Mori F, Yumoto K, Sato M, Noël M-H (2013) MCCNIES. List of strains, 9th edn. National Institute for Environmental Studies, Tsukuba

Kumar S, Stecher G, Li M, Knyaz C, Tamura K (2018) MEGA X: molecular evolutionary genetics analysis across computing platforms. Mol Biol Evol 35:1547-1549. https://doi.org/10.1093/molbev/msy096

Liss M, Kirk DL, Beyser K, Fabry S (1997) Intron sequences provide a tool for high-resolution phylogenetic analysis of volvocine algae. Curr Genet 31:214-227. https://doi.org/10.1007/s002940050198

Matsuzaki R, Hara Y, Nozaki H (2014) A taxonomic study of snow Chloromonas species (Volvocales, Chlorophyceae) based on light and electron microscopy and molecular analysis of cultured material. Phycologia 53:293-304. https://doi.org/10.2216/14-3.1

Nei M, Kumar S (2000) Molecular evolution and phylogenetics. Oxford University Press, New York 
Nozaki H (1988) Morphology, sexual reproduction and taxonomy of Volvox carteri f. kawasakiensis f. nov. (Chlorophyta) from Japan. Phycologia 27:209-220. https://doi.org/10.2216/i0031-8884-27-2-209.1

Nozaki H, Kuroiwa T (1992) Ultrastructure of the extracellular matrix and taxonomy of Eudorina, Pleodorina and Yamagishiella gen. nov. (Volvocaceae, Chlorophyta). Phycologia 31:529-541. https://doi.org/10.2216/ i0031-8884-31-6-529.1

Nozaki H, Ohta N, Morita E, Watanabe MM (1998) Toward a natural system of species in Chlorogonium (Volvocales, Chlorophyta): a combined analysis of morphological and $r b c L$ gene sequence data. J Phycol 34:1024-1037. https://doi.org/10.1046/j.1529-8817.1998.341024.x

Nozaki H, Matsuzaki R, Yamamoto K, Kawachi M, Takahashi F (2015a) Delineating a new heterothallic species of Volvox (Volvocaceae, Chlorophyceae) using new strains of "Volvox africanus". PLoS ONE 10:e0142632. https://doi. org/10.1371/journal.pone.0142632

Nozaki H, Ueki N, Misumi O, Yamamoto K, Yamashita S, Herron MD, Rosenzweig F (2015b) Morphology and reproduction of Volvox capensis (Volvocales, Chlorophyceae) from Montana, USA. Phycologia 54:316-320. https://doi.org/10.2216/15-14.1

Nozaki H, Takusagawa M, Matsuzaki R, Misumi O, Mahakham W, Kawachi M (2019) Morphology, reproduction and taxonomy of Volvox dissipatrix (Chlorophyceae) from Thailand, with a description of Volvox zeikusii sp. nov. Phycologia 58:192-199. https://doi.org/10.1080/00318884.2018. 1540238

Nozaki H, Mahakham W, Heman W, Matsuzaki R, Kawachi M (2020) A new preferentially outcrossing monoicous species of Volvox sect. Volvox (Chlorophyta) from Thailand. PLoS ONE. https://doi.org/10.1371/journal. pone.0235622

Pringsheim EG (1946) Pure cultures of algae. Cambridge University Press, London

Ronquist F, Teslenko M, van der Mark P, Ayres DL, Darling A, Höhna S, Larget B, Liu L, Suchard MA, Huelsenbeck JP (2012) MrBayes 3.2: efficient Bayesian phylogenetic inference and model choice across a large model space. Syst Biol 61:539-542. https://doi.org/10.1093/sysbio/sys029

Smith GM (1944) A comparative study of the species of Volvox. Trans Am Microsc Soc 63:265-310. https://doi.org/10.2307/3223302

Starr RC (1971) Sexual reproduction in Volvox africanus. In: Parker BC, Brown Jr RM (eds) Contribution in phycology. Allen Press, Kansas, pp 59-66

Starr RC, Zeikus JA (1993) UTEX - the culture collection of algae at the University of Texas at Austin. 1993 List of cultures. J Phycol 29(2):1-106. https:// doi.org/10.1111/j.0022-3646.1993.00001.x

Stein JR (ed) (1973) Handbook of phycological methods. Culture methods and growth measurements. Cambridge University Press, Cambridge

Tamura K, Battistuzzi FU, Billing-Ross P, Murillo O, Filipski A, Kumar S (2012) Estimating divergence times in large molecular phylogenies. Proc Natl Acad Sci USA 109:19333-19338. https://doi.org/10.1073/pnas.1213199109

Tamura K, Qiqing T, Kumar S (2018) Theoretical foundation of the RelTime method for estimating divergence times from variable evolutionary rates. Mol Biol Evol 35:1770-1782. https://doi.org/10.1093/molbev/msy044

Vos R, Lapp H, Piel W, Tamen V (2010) TreeBASE2: rise of the machines. Nat Prec. https://doi.org/10.1038/npre.2010.4600.1

Vos RA, Balhoff JP, Caravas JA, Holder MT, Lapp H, Maddison WP, Midford PE, Priyam A, Sukumaran J, Xia X, Stoltzfus A (2012) NeXML: rich, extensible, and verifiable representation of comparative data and metadata. Syst Biol 61:675-689. https://doi.org/10.1093/sysbio/sys025

Wittenberger JF (1979) The evolution of mating systems in birds and mammals. In: Marler P, Vandenbergh JG (eds) Social behavior and communication. Springer, Boston, pp 271-349. https://doi.org/10.1007/ 978-1-4615-9116-0_6

Yamamoto K, Hamaji T, Kawai-Toyooka H, Matsuzaki R, Takahashi F, Nishimura Y, Kawachi M, Noguchi H, Minakuchi Y, Umen JG, Toyoda A, Nozaki H (2021) Three new genomes in the algal genus Volvox reveal the fate of a haploid sex-determining region after a transition to homothallism. Proc Natl Acad Sci USA 118:e2100712118. https://doi.org/10.1073/pnas.2100712118

\section{Publisher's Note}

Springer Nature remains neutral with regard to jurisdictional claims in published maps and institutional affiliations.

\section{Submit your manuscript to a SpringerOpen ${ }^{\circ}$ journal and benefit from:}

- Convenient online submission

- Rigorous peer review

- Open access: articles freely available online

- High visibility within the field

- Retaining the copyright to your article

Submit your next manuscript at $\boldsymbol{\nabla}$ springeropen.com 